\title{
Monitoring above-ground forest biomass: A comparison of cost and accuracy between LiDAR assisted multisource programme and field-based forest resource assessment in Nepal
}

\begin{abstract}
P. N. Kandel ${ }^{1}$
Analyzing forest monitoring costs and accuracy of forest carbon stock estimates are important criteria in the framework of Reducing Emission from Deforestation and Forest Degradation (REDD), because Monitoring, Reporting and Verification (MRV) system has been seen as an investment that aims to generate financial benefits to forest owners. Thus, comparisons of cost efficiency and accuracy were carried out between the LiDAR (Light Detection and Ranging) Assisted Multisource Programme (LAMP) and the field-based multisource Forest Resource Assessment (FRA) applied in the $23500 \mathrm{~km}^{2}$ Terai Arc Landscape (TAL) of Nepal in 2011 to estimate Above Ground Biomass (AGB). The model-based LAMP was applied by integrating 5\% LiDAR sampling, wall to wall RapidEye satellite image and field sample plot inventory. The design-based FRA was carried out to generate comprehensive forest resource information. Administrative and initial variable costs of both approaches were calculated separately, and converted to unit costs for comparison. To compare the subsequent forest monitoring costs, cumulative costs were derived on the basis of the calculated present variable items and expenditures. The accuracies were calculated by using mean error of mean biomass estimates (tons/ha) at different spatial scales ranging from 1 to 350,000 ha forests. Design-based FRA was found to be cost-efficient (USD 0.22/ ha) as compared to the LAMP approach (USD 0.28/ha) for baseline data collection, whereas administrative cost of multisource FRA (USD 0.26/ha) was significantly higher. Although a huge amount of data were generated through multisource FRA in each cycle, the LAMP approach appears to be cost-efficient to estimate AGB in subsequent forest inventory. The mean errors in the LAMP-derived mean biomass estimate were significantly smaller at all spatial resolutions than the FRA-plotderived mean biomass estimate. The study concludes that spatial accuracy of LAMP is good enough to estimate biomass stock of Community Forests (CFs) where average size of CF is 150 ha in the study area.
\end{abstract}

\section{Key words: Above-ground biomass, cost, accuracy, LiDAR, Forest Resource Assessment}

$\mathrm{F}$ Torests act as carbon sink, but turn into a source of carbon emissions when they degrade. As a consequence, political and public attentions to the world's forests have drastically increased due to the significant role of forests in the global carbon cycle (FAO, 2010; IPCC, 2007). Tropical forests cover $15 \%$ of the world's land surface, and hold about $25 \%$ of the carbon in the terrestrial biosphere, emit 15-20\% of the total carbon dioxide in the atmosphere every year due to deforestation and forest degradation (FAO, 2010; IPCC, 2007).
Recognizing this prospect, the United Nations Framework Convention on Climate Change (UNFCCC) agreed to encourage reductions in greenhouse gas emissions from forests via REDD+ programme (Asner et al., 2010; FAO, 2010; UNFCCC, 2009). As a result, REDD+ has become an international policy instrument to mitigate climate change by reducing carbon emissions caused by deforestation and forest degradation, and by increasing carbon uptake through forest restoration and sustainable forest management (Herold and Skutsch, 2011;

FRA Nepal Project, Department of Forest Research and Survey, Ministry of Forests and Soil Conservation,

Kathmandu, Nepal. E-mail: pkkandelnepal@gmail.com 
IPCC, 2006). However, effective implementation of REDD+ strategy depends on cost-effective forest monitoring systems to generate accurate baseline statistics of forest biomass, carbon stocks and emission levels (Asner et al., 2010; Asner, 2009).

Forest inventory methods have changed in the course of time due to the continuous technological advancement (Kandel, 2010; Gatziolis and Andersen, 2008). The key driving force behind the development of different FRA methods is the goal of obtaining accurate forest information at low cost (Tomppo et al., 2008; Kangas and Maltamo, 2006).

In the past, intensive field-based FRA focused on timber production and applied for estimating tree volume, growing stock and growth (Hummel and O'hara, 2008). Although traditional approach is accurate method, rigorous field measurement is time-consuming, costly, and difficult to implement in unreachable extensive forest areas.

Satellite Remote Sensing (RS) has become key tool to collect large amounts of image data over a wide geographical area with high temporal frequency and provide $2 \mathrm{D}(\mathrm{x}, \mathrm{y})$ information on species composition. However, optical RS cannot penetrate through the forest canopy to generate information about forest structure (Gautam et al., 2010). Besides, intensive field inventory and ground verification are required to validate the data and to generate tree-level statistics (Gautam and Kandel, 2010).

Light Detection and Ranging (LiDAR) is an active RS technology that is able to penetrate the vertical profile of dense forest canopy and quantify its structure (Asner et al., 2012; Pascual et al., 2010; Gatziolis and Andersen, 2008). Compared to traditional passive optical RS, LiDAR has the capacity to capture 3D (x, y, z) data of objects, and can precisely estimate height and size of individual trees or forest stands and thereby volume and AGB (Lim et al., 2003; Nelson et al., 2003). However, a key obstacle in using LiDAR is due to its relatively high cost for scanning in challenging flying condition (Asner et al., 2010; Gautam et al., 2010; Hummel et al., 2011; Næsset, 2002a,b, and 2009).

When combining LiDAR from sample areas with satellite data covering the entire area of interest and in-situ measurements at sample locations, high-resolution maps of forest carbon stocks and emission can be produced in an efficient way (Asner et al., 2010; Arbonaut, 2010). The integrated approach is known as the LAMP - a term that was coined by the World Wildlife Fund U.S. (WWF US) and the Arbonaut, Finland in the early 2011. LAMP has been tested in Peru, Laos, Madagascar, Colombia and Nepal. However, a cost and accuracy analysis that would allow a comparison between the LAMP approach and field-based forest inventory methods has not been carried out so far.

Comparison of cost and accuracy of different FRA approaches applied for the same objective such as monitoring forest carbon stocks and emissions has become one of the key research areas in forestry in order to draw conclusions on their cost efficiency, robustness and accuracy (Hummel et al., 2011). This paper presents the results of a study which compares the cost and accuracy of LAMP and multi-source FRA methods applied in TAL-Nepal for the estimation of AGB.

\section{Materials and methods}

\section{Study area}

The study was conducted within the Terai Arc Landscape (TAL) that extends between Nepal and India, and includes two globally outstanding ecoregions viz. the Terai-Duar Savanna Grasslands, and the Himalayan Subtropical Broadleaf Forests (Gurung and Joshi, 2009). The TAL covers an area of $23,500 \mathrm{~km}^{2}$ within Nepal, and is bounded by Bagmati River in the East, Mahakali River in the West, Siwalik ridge in the North and India in the South (Fig. 1).

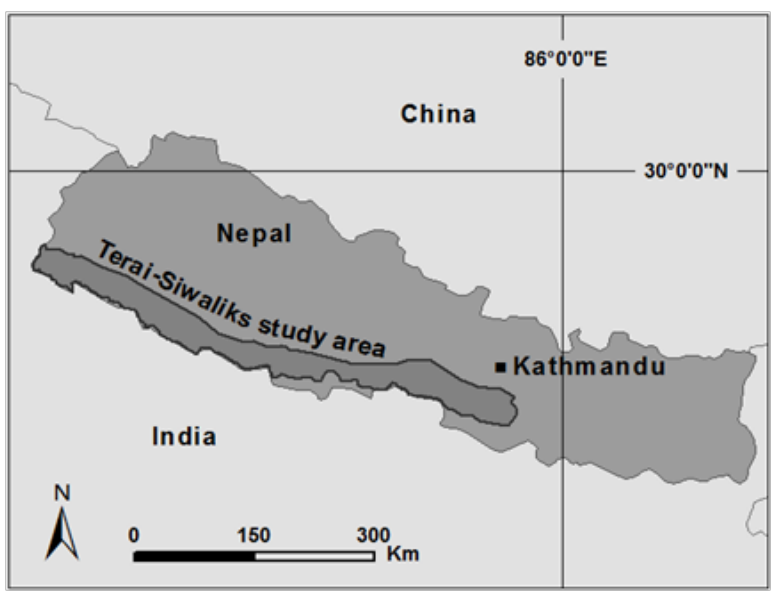

Fig. 1: Map showing the study area in the Terai Arc Landscape 
Altitude varies from $300 \mathrm{~m}$ in the South to 1,500 $\mathrm{m}$ in the northern hills above mean sea level. The area is a spatial mosaic of tropical and subtropical forest types, and covers $75 \%$ of the remaining forests of Terai and the foot hills of the Siwaliks (HMGN/ MFSC, 2004; HMGN/ADB/FINNIDA, 1988). The region is home to the world's most impressive wildlife species such as Royal Bengal Tiger, the Greater One-horned Rhinoceros and the Asian Elephant (Joshi and Bhatta, 2010). The area is inhabited by 6.7 million people, and the majority of them are rural poor (Gurung and Kokh, 2011). As a result, forest resources have declined in extent and quality due to deforestation and degradation.

\section{Inventory methods considered in the study}

\section{LiDAR assisted multisource programme}

LiDAR-data were collected from $5 \%$ of the study area. For the LiDAR campaign, 20 rectangular forest blocks of $5 \mathrm{~km} \times 10 \mathrm{~km}$ size were designed by a weighted random sampling. Wall-to-wall Airborne Laser Scanning (ALS) was conducted during March and April 2011 using a Leica ALS50-II Scanner. Average recorded point density was 1.26 pulses $/ \mathrm{m}^{2}$.

Systematic cluster sampling was applied to collect field data in the LiDAR sample areas. Six clusters were designed in each LiDAR block. Altogether, 792 forest-located circular plots of size $500 \mathrm{~m}^{2}$ were measured in the field. The measurements at tree-level included all living trees and shrubs above $5 \mathrm{~cm}$ diameter within the plot area. Plot volume and biomass were calculated using species-group specific volume and biomass equations prepared by Sharma and Pukkala (1990).

LiDAR metrics describing the canopy height distribution are used to predict growing stock, biomass and other related characteristics of a forest stand (Lim et al., 2003; Næsset, 2002a). The LiDAR model is established by regressing field measurements with $30 \mathrm{LiDAR}$ variables defined by Junttila et al., 2010. The selection of variables is done using the Sparse Bayesian methodology (Junttila et al., 2008). The ArboLiDAR tools developed by Arbonaut, Finland were used to apply this method.

\section{Field-based Multisource FRA approach}

The FRA Nepal Project (2010-2014) has applied a stratified two-phase systematic cluster sampling. In the first phase sampling, $4 \mathrm{~km}$ by $4 \mathrm{~km}$ systematic grids were overlaid for visual interpretation. Out of the total, 4883 (56\%) points were located in the forests. Altogether, 128 sample clusters consisting of 676 sample points which represent about $13.8 \%$ points of the first phase forest-area samples were selected for field inventory.

In the Terai region, each cluster consisted of a group of 4 sample plots while there were 6 plots per cluster in the Siwaliks. A concentric circular sample plot with radii thresholds of $20 \mathrm{~m}, 15 \mathrm{~m}$, $8 \mathrm{~m}$ and $4 \mathrm{~m}$ was designed for tallying and measuring different size of trees. Field inventory was carried out by a number of field inventory crews. The measured tree characteristics were used to calculate the volume of each species at plot-level, later extrapolated to the whole target area and finally estimated per unit area (Sharma and Pukkala, 1990).

\section{Costs of forest inventory}

Hardcastle and Baird (2008) have described the cost of forest inventory under variable and fixed/ administrative costs. Variable costs depend on methods, spatial coverage, required accuracy, sampling intensity, materials to be used and the capacity of the executing organization. The administrative costs include costs of planning and organizing sampling events such as staffing, formulating inventory tools and techniques, personnel/experts involved, procurements and other costs which do not much vary with sampling design and other variables of inventory, if system is well institutionalized. In the case of the projectbased FRA, the total cost becomes the allocated budget to perform the task.

\section{Extent of variable costs of LAMP}

Variable costs of LAMP comprise the expenditure required for: wall-to-wall LiDAR scanning in 20 sample blocks, in situ measurements at 792 field plots; purchase of RapidEye satellite imagery, data processing, modeling (LiDAR model and satellite-based model) and biomass estimation for the whole study area. The cost-related data were collected from the records of the FRA Nepal Project and Arbonaut, Finland. The costs for data processing and model building were derived from the number of working days spent on these tasks and the respective hourly rates of the experts involved. 
Variable cost magnitudes of field-based FRA

Several variable costs were associated during the implementation of field-based FRA. All relevant cost items, their composition and data sources are presented in table 1.

The second phase field inventory was organized in a mission-wise approach by sending the crews to the locations of different field sample clusters. To derive the related costs, the average number of days spent by a crew for the field inventory and the average number of sample plots measured by a crew in each mission were calculated. On an average, the field inventory crews spent 24 days in a mission, and measured 12 sample plots. Including all the expenditure items, the average total cost of each crew mission was computed. Cost per plot was figured out by using the following formula:

Cost $/$ plot $=$ Total cost per crew mission $/ 12$ plots

The total cost was determined by adding the overall cost of all direct expenses. Finally, perhectare cost for the study area was derived.

\section{Estimation of subsequent monitoring cost}

Subsequent forest monitoring is needed in successive cycle to update the forest information (FAO, 2010; Tomppo et al., 2008; Kangas and
Maltamo, 2006). Field-based FRA approach necessitates repeating forest inventory in the same way during successive time periods. However, LAMP needs to update the model by interpretation of new satellite images for successive years at least does not repeat other items up to certain cycles (Asner et al., 2010; Gautam et al., 2010; Lim et al., 2003; Næsset, 2002b). The LAMP model can also be applied to estimate historical biomass from satellite imagery of the past. In the case of TAL-Nepal, after collecting the baseline data, three succeeding cycles of five year interval have been set by assuming that the LAMP model does work up to the next 15 years. In this case, cost only requires for updating the model through interpretation and processing of new satellite images to produce AGB estimates.

In consequence, a postulation has been set that includes the base line data collection, forest monitoring up to the next three rounds is a single task required for MRV. An additional assumption is that both systems will be institutionalized within the Department of Forest Research and Survey (DFRS) of Nepal thus, no cost is required to hire international experts. Hence, calculation of cumulative cost is required for the set subsequent forest monitoring series. We approach this build up of activity cost so that each successive total cost includes activity costs

Table 1: Details of cost items involved in field-based multisource FRA

\begin{tabular}{|c|c|c|}
\hline Expenditure items & Details under each items & Data sources \\
\hline - Procurement of satellite imagery & $\begin{array}{l}\text { - Cost calculated from actual price re- } \\
\text { quired to buy RapidEye imagery. }\end{array}$ & FRA Nepal Project \\
\hline - Training cost to train field crews & $\begin{array}{l}\text { - Cost required for training the inventory } \\
\text { crew members involved in field plot } \\
\text { measurement. }\end{array}$ & FRA Nepal Project \\
\hline $\begin{array}{l}\text { - First-phase sampling (image } \\
\text { interpretation) }\end{array}$ & $\begin{array}{l}\text { - Cost required for interpretation of the } \\
\text { points within the study area. }\end{array}$ & FRA Nepal Project \\
\hline $\begin{array}{l}\text { - Second-phase field inventory } \\
\text { (in situ measurement) }\end{array}$ & $\begin{array}{l}\text { - Preparatory cost } \\
\text { - Hardship allowance for field crews and } \\
\text { local staff paid by the Project } \\
\text { - Expenses required for social survey } \\
\text { - Accommodation cost for field crews } \\
\text { - Cost for vehicles and fuel } \\
\text { - Salary for crew members } \\
\text { - Field-gear }\end{array}$ & $\begin{array}{l}\text { Mission-wise record } \\
\text { from FRA Nepal } \\
\text { Project }\end{array}$ \\
\hline $\begin{array}{l}\text { - Quality control of second-phase } \\
\text { field inventory }\end{array}$ & About $7 \%$ cost of second-phase sampling & Quality control team \\
\hline - Data entry, processing analysis & & \\
\hline
\end{tabular}


that precede it (Jhingan, 2002). Although the per hectare cost for consecutive inventory cycles could be significantly increased in the future, due to increasing prices of materials and labors, the given estimates of future inventory costs (Table 4) were derived on the basis of the calculated present initial expenditures which reveal the indicative minimum cumulative cost required for successive cycles. The set of assumptions allow us to compare cost efficiency between the two approaches up to the defined sequence of measurement cycles.

\section{Estimation of method accuracy}

The Mean Square Error of an estimator, MSE or $\operatorname{ME~}(\theta)$ assesses the quality of an estimator in terms of its variation and unbiasedness. Two or more statistical models applied for the same purpose can be compared using the values of the ME $(\theta)$ to explain the reliability of two sets of observations (Lebanon, 2010; Moore and McCabe, 2001). For the purpose of this study, both field plot-based FRA method and the LiDAR assisted LAMP approach were compared with respect to their accuracy in estimating mean AGB at different spatial scales. The $\operatorname{ME}(\theta)$ is calculated as the root of the sum of the variance and the squared bias of the estimator:

$$
M E(\theta)=\sqrt{\operatorname{var}(\theta)+\operatorname{bias}(\theta)^{2}}
$$

In order to derive the mean error at different spatial scales, the formula was modified by replacing variance with the square of the standard error of the mean. The standard error of the mean is the standard deviation of the error in the sample mean relative to the true mean:

$$
S E_{x}=\frac{s}{\sqrt{n}}
$$

Where $\mathrm{s}$ is the standard deviation of the sample and $\mathrm{n}$ is the sample size (number of observations).

Using the sample size as an indicator of the spatial scale (area) at which a mean estimate is produced, the scale-dependent mean error was calculated as:

$$
\operatorname{ME}(\theta)_{n}=\sqrt{\frac{s^{2}}{n}+\operatorname{bias}(\theta)^{2}}
$$

Where $\mathrm{s}$ is the standard deviation of above-ground biomass in FRA plots which was considered the true standard deviation of biomass, and $n$ is the number of FRA plots or LAMP estimates respectively for a certain area.

For the FRA approach, $\mathrm{n}$ was scaled according to forest area, adopting an ideal case of equal spatial distribution of field plots over the forest:

$$
n_{R}=\frac{R}{A} \times n_{F R A}
$$

Where $\mathrm{R}$ is the forested area (ha) from which the mean estimate is produced, $\mathrm{A}$ is the total forested area $(350,000 \mathrm{ha})$ according to the available vegetation map, and $n$ FRA is the total number of FRA plots.

For the LAMP approach, $\mathrm{n}$ is equal to the area from which the estimate is produced. The LAMP method produces biomass estimates at 1-hectare resolution. That means LAMP produced 350,000 samples in 350,000 ha but field-based FRA approach designed only 150 samples.

The FRA approach was considered an unbiased method because it is a design-based method that better follows to the laws of statistics, so that in this case the formula could be simplified to the formula for standard error of the mean (Equation 2). The bias of LAMP was calculated by comparing LAMP estimates at FRA-plot locations with the corresponding FRA-based AGB values. The accuracy of the LAMP approach was calculated using equation 3 .

\section{Results and discussion}

\section{Total and administrative costs}

Deducting the cost for LiDAR as indicated in the Project Document, the total budget of the FRA Nepal project is USD 7099973.00 allocated to conduct comprehensive national FRA. On the other hand, the LAMP was a sub-approach under the project conducted at sub-national scale to estimate AGB. The total cost of LAMP was USD 728957.00 which include USD 265320.00 allocated by the FRA Nepal Project. The remaining budget was contributed by the WWF US/Nepal and the Arbonaut, Finland. On the basis of the total allocated budget, the cost for the fieldbased FRA was USD 0.48/ha; the cost for LAMP being USD 0.31/ha. The administrative cost for the field-based FRA becomes USD 0.26/ha as compared to USD $0.03 /$ ha in the case of LAMP. 


\section{Initial variable cost}

\section{Model-based LAMP approach}

In the study area, the total variable cost for LAMP was USD 655037.00, indicating USD 0.28/ha. A break-down of the entire variable costs under each item and cost per hectare are presented in table 2 . The result reveals that LiDAR scanning is the most expensive comprising $44 \%$ of the total cost, followed by the field inventory which forms $31.6 \%$ of the cost.

Table 2: Initial cost of LAMP over the entire study area

\begin{tabular}{lcc}
\hline \multicolumn{1}{c}{ Cost items } & $\begin{array}{c}\text { Total cost, } \\
\text { USD }\end{array}$ & $\begin{array}{c}\text { Cost/ha, } \\
\text { USD }\end{array}$ \\
\hline $\begin{array}{l}\text { LiDAR scanning } \\
\text { Procurement of } \\
\text { satellite imagery }\end{array}$ & 18480400.00 & 0.125 \\
$\begin{array}{l}\text { Field inventory } \\
\text { Modeling LiDAR } \\
\text { data with field } \\
\text { plots }\end{array}$ & 207240.00 & 0.0079 \\
$\begin{array}{l}\text { LAMP model } \\
\text { building and data } \\
\text { processing }\end{array}$ & 115685.00 & 0.089 \\
\hline Total cost & $\mathbf{6 5 5 0 3 7 . 0 0}$ & $\mathbf{0 . 2 8 1 8}$ \\
\hline
\end{tabular}

\section{Field-based Multisource FRA}

In comparison to LAMP, the total variable expense for the multisource FRA method amounts to USD 522450 for the same study area, which comprises USD 0.22 per hectare. A break-down of the total cost under each item and cost per hectare are presented in table 3.

\section{Subsequent monitoring cost}

For future monitoring, the costs for LAMP are only related to model updates and data analysis for each successive LAMP cycle. These costs equal about USD 0.05 /ha which was integrated in a cumulative figure for each successive cycle. Table 4 lists the cumulative cost for LAMP up to third consecutive series with USD $0.43 /$ ha. In comparison, in the case of field-based multisource FRA, almost the same variable costs are involved in every consecutive inventory. Therefore, the initial cost of USD 0.22 /ha was added for each inventory cycle. As a result, the cumulative cost per hectare (USD 0.44) for the approach is higher than the cost of LAMP (USD 0.33) already from the second inventory cycle onwards. By the fourth cycle, the cost for the design-based FRA approach reaches USD $0.88 /$ ha compared to USD 0.43 /ha for the LAMP approach.

Table 4: Cumulative cost of multiple inventory cycles* of LAMP and field-based FRA

\begin{tabular}{lcccc}
\hline \multicolumn{1}{c}{$\begin{array}{c}\text { Forest } \\
\text { monitoring } \\
\text { approaches }\end{array}$} & \multicolumn{3}{c}{$\begin{array}{c}\text { Estimated cumulative cost } \\
\text { (USD) for successive }\end{array}$} \\
\cline { 2 - 5 } & $\begin{array}{c}\text { Baseline } \\
\text { cost }\end{array}$ & $\begin{array}{c}\text { First } \\
\text { cycle }\end{array}$ & $\begin{array}{c}\text { Second } \\
\text { cycle }\end{array}$ & $\begin{array}{c}\text { Third } \\
\text { cycle }\end{array}$ \\
\hline $\begin{array}{l}\text { Model- } \\
\text { based }\end{array}$ & 0.28 & 0.33 & 0.38 & 0.43 \\
LAMP & & & & \\
$\begin{array}{l}\text { Designed- } \\
\text { based }\end{array}$ & & & & \\
$\begin{array}{l}\text { Multisource } \\
\text { FRA }\end{array}$ & 0.22 & 0.44 & 0.66 & 0.88 \\
*one cycle = five years & & & \\
\hline
\end{tabular}

Table 3: Baseline cost (USD) of the multisource FRA method in TAL-Nepal

\begin{tabular}{lcc}
\hline \multicolumn{1}{c}{ Cost items } & Total cost, USD & Cost/ha, USD \\
\hline Procurement of satellite Image & 18480.00 & 0.0079 \\
Procurement of ancillary data and maps & 2500.00 & 0.0011 \\
First phase sampling & 3000.00 & 0.0013 \\
Method development and testing & 2000.00 & 0.001 \\
Training cost & 8000.00 & 0.0034 \\
Cost for second phase field inventory & 359219.00 & 0.15 \\
Data entry, processing and analysis & 129250.00 & 0.055 \\
\hline Total cost & $\mathbf{5 2 2 4 5 0 . 0 0}$ & $\mathbf{0 . 2 2}$ \\
\hline
\end{tabular}


Accuracy comparison

Table 5 demonstrates the behaviour of the mean error (ME) in mean biomass estimates produced by FRA and LAMP approaches at different spatial scales. The larger the estimation area, the lower is the mean error of the estimate.

Table 5. Mean error of mean biomass estimates at different scales for FRA and LAMP methods

\begin{tabular}{ccc}
\hline $\begin{array}{c}\text { Resolution } \\
\text { (hectares } \\
\text { of forest) }\end{array}$ & $\begin{array}{c}\text { Mean error } \\
\text { in FRA-plot- } \\
\text { derived mean } \\
\text { biomass estimate } \\
\text { (tonnes/ha) }\end{array}$ & $\begin{array}{c}\text { Mean error in } \\
\text { LAMP-derived } \\
\text { mean biomass } \\
\text { estimate } \\
\text { (tonnes/ha) }\end{array}$ \\
\hline 1 & 6243.95 & 129.29 \\
10 & 1974.51 & 40.97 \\
100 & 624.39 & 13.21 \\
1,000 & 129.26 & 4.90 \\
5,000 & 88.30 & 3.26 \\
10,000 & 62.44 & 2.99 \\
50,000 & 27.92 & 2.76 \\
100,000 & 19.75 & 2.73 \\
350,000 & 10.55 & 2.71 \\
\hline
\end{tabular}

The results indicate that mean error of LAMP at 1 ha resolution is 129.29 tonnes/ha and after that it gradually decreases with increasing estimation area and reaches an asymptotic limit of 2.7 tonnes/ ha at a 350,000 ha spatial resolution, which is the bias detected in the method. After that limit, mean error of estimate remains the same, even when the estimation area is increased. In comparison, the mean error of the FRA estimate at 1 ha is 6243.95 tonnes/ha which is very high, but afterwards slowly decreasing with increasing forest areas, and goes down to 10.6 tonnes/ha when estimation forest area reaches 350,000 ha.

\section{Discussion}

Nepal is in a REDD-readiness/demonstration phase, and needs to pay special consideration to the cost-efficiency and accuracy of the proposed REDD monitoring concepts. It is good practice to appraise alternative FRA methods in terms of cost-efficiency and accuracy which eventfully facilitates to determine accurate and reliable methods required to meet higher tiers approach for the estimation of carbon stock changes in cost effective way (IPCC, 2006). This study evaluated and compared the cost-efficiency and accuracy between the LAMP approach and the filed-based FRA method applied in Nepal's TAL area for the purpose.

Hardcastle and Baird (2008) argue that the cost for forest inventory would be the total budget of a project, and in such case, variable and administrative costs are assumed to be equal. However, this study reveals that the administrative cost (USD 0.26/ha) for field-based FRA is higher than the variable cost (USD $0.22 / \mathrm{ha}$ ). The reason behind is that about $46 \%$ project cost goes to the salary of experts (international 39\% and regional $7 \%$ ) and about $16 \%$ is under operating cost $(\mathrm{GoN} /$ GoF, 2010). It indicates that forest monitoring system has not been fully institutionalized, and the capacity of the executing agency needs to be further strengthened. The cost analysis explains that administrative cost of the FRA Nepal Project appears to be significantly higher than the LAMP, since the FRA Nepal Project has been designed for five years (2010-2014) to conduct nationallevel FRA; however, LAMP was applied within three month-period for estimating only AGB in the targeted area.

The results presented in this study reveal that model-based LAMP was more expensive in terms of variable cost (USD 0.06/ha) as compared to the design-based FRA for collecting baseline data. Although the cost difference between two approaches seems to be insignificant, the fieldbased FRA process has collected data on more attributes as compared to the LAMP approach. It is obvious that multisource FRA is more cost efficient than the LAMP in terms of baseline data collection for the whole TAL area.

The International Panel on Climate Change (IPCC) estimates $£ 0.025-£ 0.30 /$ ha cost of national forest carbon inventories (Hardcastle and Baird, 2008). LiDAR-based forest inventory has been recently applied in different parts of the world to estimate forest carbon stock. Carnege Institution for Science, USA operated LAMP in Peru, Madagascar and Colombia to estimate forest carbon stocks and emission by using 2.8$12 \%$ LiDAR sampling, freely available Landsat Thematic Mapper (TM) image, limited field measurement and automated non-commercial CLASlite software at cost ranging from USD 0.20 to USD 0.06 ha $^{-1}$ (Asner et al., 2010, 2011; Asner, 2009). For the 4.3 million ha Peruvian Amazon forest, $12 \%$ LiDAR sampling was used, and only 131 large field plots (radius $30 \mathrm{~m}$, area 
per plot 0.2827 ha, total area $37 \mathrm{ha}$ ), and 37 small field plots (radius $3 \mathrm{~m}$, area per plot $28.27 \mathrm{~m}^{2}$, total area $1,046 \mathrm{~m}^{2}$ ) were measured in the study area to calibrate LiDAR metrics of aboveground carbon at USD 0.08/ha (Asner et al., 2010). This study discloses that the cost of LAMP in Nepal is higher than in those countries. One of the reasons for this is that the intensity of field sampling was significantly higher (radius $12.62 \mathrm{~m}$, area per plot $500 \mathrm{~m}^{2}$, plot measured 792 and total area $39.6 \mathrm{ha}$ ) in Nepal to represent the vegetation types and regional variation. Field inventory did cost second highest amount (USD 0.089/ha) after LiDAR scanning. Moreover, employing international experts for data processing and model building increased the cost.

The analysis of variable cost of multisource FRA (Table 3) shows that the field inventory forms the most expensive component. On an average, the cost per plot was USD 531.50; the total estimated cost to measure 676 concentric circular plots being USD 359,219.00 (71\%). Data entry and processing needed approximately $23 \%$ of the total cost. The expenditure for the remaining items seems to be insignificant.

The results of subsequent variable cost comparison (Table 4) show that the minimum cumulative cost for field-based FRA is significantly increasing from the first cycle of inventory, and reaches more than double the cost of LAMP up to the third cycle. The reason for this is that all the variable cost items were included in every successive cycle for multisource FRA processes, whereas in the case of LAMP, the only cost required is for model updating through new satellite image interpretation. As a result, the LAMP approach appears to be more cost efficient in subsequent forest carbon monitoring.

Multisource FRA is a design-based method, whereas LAMP is a model-based approach. The key difference between the two approaches lies in source of randomness they utilize (Särndal, 1978). In designed-based sampling theory, the source of randomness is the probability introduced by sampling design to the various subsets of population. However, in a model-based approach, all the randomness in the inference is due to the population, and not due to the sampling method adopted as in a design-based approach (Kangas and Maltamo, 2006; Kangas, 1993).
To attain Tier 3 in REDD+, spatially explicit estimates are required to determine reliable forest carbon stock difference. LiDAR-assisted inventory is the most accurate method to provide higher-resolution biomass estimates and carbon stock (Asner et al., 2012; Arbonaut, 2010; IPCC, 2006; Næsset, 2002a,b). The ME of an estimate, $\operatorname{ME}(\theta)$ is a useful criterion to compare two estimators, the one with smaller $\operatorname{ME~}(\theta)$ is said to be a more accurate approach than the other (Kohl et al., 2011). For the purpose of this study, the dataset generated by LAMP and multisource FRA approaches were used to estimate mean AGB. Comparison of accuracy was done by calculating $\operatorname{ME}(\theta)$.

Table 5 presents the ME of mean biomass estimates at different scales ranging from 1 ha to 350,000 ha forest for both inventory approaches. The results clearly disclose that the biggest difference between the two approaches is spatial resolution. The ME in the LAMP-derived mean biomass estimate is found to be significantly smaller at all spatial resolutions than the one in the FRA-plot derived mean biomass estimate. The $\mathrm{ME}$ at 1000 ha scale of field-based FRA becomes 129.26 tonnes/ha as compared to the ME at 1000 ha spatial resolution of LAMP estimate (4.9 tonnes/ha). Thus, accuracy of LAMP is enough to estimate $\mathrm{AGB}$ up to management regimes.

Community Forestry (CF) is one of the key strategies of forest management in Nepal, where national forests have been handed over to the local Forest Users Groups (CFUGs) for their autonomous management and use. CFUGs are authorized local organizations, and possess right to claim for carbon credit gained due to the protection and management of handed over forests. To date, nearly 18,000 CFUGs are managing about 1.7 million ha forest $(22 \%$ of the total forest area) throughout the nation (DoF, 2012). In the TAL area, there are more than 1600 CFUGs managing nearly 240,000 ha forest (DoF, 2012; Joshi and Bhatta, 2010). The statistics shows that average size of community forest is 150 ha in the TAL region. The results in table 4 illustrate that the mean error in LAMPderived biomass is 13.21 tonnes/ha at 100,000 ha spatial extent. However, the same accuracy is not possible through field-based FRA. As a result, the accuracy of LAMP is good enough to estimate biomass stock of community forests. 


\section{Conclusion}

Selection of the most cost efficient and accurate forest monitoring method is a matter of optimization which demands comparative study between the approaches. This study tried to compare the costs and Nepal. The administrative cost of the field-based FRA is higher than its variable cost due to the involvement of international and regional experts in the Project. This study concludes that the cost of forest monitoring greatly depends upon national capacity. National-level FRA in Nepal has been conducted on project-basis as the organizational capacity of the executing agency needs to be further strengthened. Therefore, it is recommended that forest monitoring system in Nepal should be periodic and mandatory, and ensured by policy instruments and national forestry programme.

Within the stipulated forest inventory schemes, variable expenses of the model-based LAMP was found to be more costly in baseline data collection than that of the field-based FRA. On the contrary, the model-based LAMP is more cost efficient in subsequent forest monitoring. This study indicates that the model-based LAMP is more cost efficient as compared to the field-based FRA to monitor forest carbon stocks in short period of time, and at the same time, does not require whole processes up to certain inventory cycles. However, the cost required for the purpose within the TAL area in Nepal was found to be higher than that reported in other countries. Hence, the intensities of LiDAR sampling and field-plot measurement seem to be further analyzed.

Theoretically, smaller the mean error of the estimate, higher is the accuracy. The result reveals that mean errors of LAMP-derived estimates are significantly smaller than the mean error of the FRA-plot-derived estimate at different spatial scales ranging from 1 to 350,000 ha forest area. For this reason, the study concludes that the LAMP approach is highly accurate to estimate AGB at small spatial scale even at managementlevel forest regime, e.g. community forests of Nepal.

The choice of inventory method should always be made depending on the expected outcomes and forest variables to be measured. Through fieldbased multisource FRA method, information about a vast number of target variables can be collected, ranging from tree-level characteristics to biodiversity and soil. A model-based LAMP method covers much less forest variables, and cannot replace a multisource inventory. However, it produces biomass and carbon stock estimates at high spatial resolution suitable for IPCC Tier 3 level, which is difficult to achieve with fieldbased multisource inventory.

\section{Acknowledgements}

I am grateful to Dr. Kesab Dutta Awasthi, Professor, Institute of Forestry, Pokhara, Nepal for supervising the whole study. My gratitude goes to Dr. Tuomo Kotimaki, Associate Professor, Department of Mathematics and Physics, Lappeeranta University of Technology, Finland for facilitating to conceptualize this highly demanded study. I am thankful to Arbonaut, Finland and its team for inviting me to attend a LAMP training course which became exceptionally helpful to me to understand Arbo LiDAR tool and LAMP data processing processes. Thanks also go to Ms. Katja Gunia, Mr. Basanta Gautam, Ms. Katri Tegel and the scientific team of Arbonaut, Finland for providing substantial technical inputs during study period. I am thankful to Mr. Sahas Man Shrestha, Director General (DG), and Mr. Hasta Bahadur Thapa, Deputy DG of Department of Forest Research and Survey, Nepal for reviewing the article. Eventually, I must thank Mr. Michael Hawkes, the existing Chief Technical Advisor (CTA) and Mr. Tuomo Kotimaki previous CTA of FRA Nepal project for creating enabling environment to conduct this study.

\section{References}

Arbonaut. 2010. ArboLiDAR: Monitoring Change in Carbon Stocks and Achieving REDD Target. A Brochure, www.arbonaut. com.

Asner, G. P., Powell, G. V. N., Mascaro, J., Knapp, D. E., Clark, J. K., Jacobson, J., Kennedy-Bowdoin, T., Arvindh, B., PaezAcosta, G., Victoria, E., Secada, L., Valqui, and Hughes, R. F. 2010. High-Resolution Forest Carbon Stocks and Emission in the Amazon. http//www.pnas.org/content/ early/2010/08/30/1004875107.short (Accessed on 8 September 2010).

Asner, G. P. 2009. Tropical forest carbon assessment: integrating satellite and airborne mapping approach. Environmental Research 
Letters 4: 1-11.

GoN/GoF. 2010. Forest Resource Assessment in Nepal. Bilateral Cooperation between Government of Nepal (GoN) and Government of Finland (GoF), Final Revised Project Document, June 23, 2010, Kathmandu, Nepal.

DoF. 2012. Community Forest User Group (CFUG) database record available in MIS on August 31, 2012. Community Forestry Division, Department of Forest (DoF), Kathmandu, Nepal.

FAO. 2010. Global Forest Resource Assessment (GFRA) 2010. FAO Forestry Paper 163. Food and Agriculture Organization (FAO) of the United Nations, Rome, Italy.

Gatziolis, D. and Andersen, H. E. 2008. A Guide to LiDAR Data Acquisition and Processing for the Forests of Pacific Northwest. General Technical Report PNW-GTR-768, July 2008. United States Department of Agriculture (USDA) Forest Service Pacific Northwest Research Station, USA.

Gautam, B. R. and Kandel, P. N. 2010. Working Paper on LiDAR Mapping in Nepal. Approved from the Ministry of Forests and Soil Conservation on 26 March 2010. http:/www.forestrynepal.org/publication/ article/4771 (Accessed on 15 July 2010).

Gautam, B. R., Tokola, T., Hamalainen, J., Gunia, M., Peuhkurinen, J., Parviainen, H., Leppanen, V., Kauranne, T., Havia, J., Norjamaki, I. and Sah, B. P. 2010. "Integration of Airborne LiDAR, Satellite Imagery and Field Measurements using a Two-phase Sampling Method for Forest Biomass Estimation in Tropical Forests" a paper presented at International Symposium on "Benefiting from Earth Observation", 6 October 2010, Kathmandu, Nepal .

Gurung, M. B. and Joshi, C. 2009. Assessment of Forest Carbon Potential of Riverine Forests at the Khata Corridor and LamahiMahadevpuri Complex, Nepal. Baseline Report, WWF Nepal.

Gurung, M. B. and Kokh, M. 2011. Forest Carbon Accounting Study Report: Baseline, Optimum Sequestration Potential and Economics of REDD+ in the Terai Arc Landscape of Nepal. WWF Nepal.
Hardcastle, P. D. and Baird, D. 2008. Capability and Cost Assessment of the Major Forest Nations to Measure and Monitor Their Forest Carbon for Office of Climate Change. Final Report, 7 April 2008. www. occ.gov.uk.

Herold, M. and Skutsch, M. 2011. Monitoring, reporting and verification for national REDD+ programmes: two proposals. Environmental Research Letters 6: 1-10.

HMGN/MFSC. 2004. Nepal Biodiversity Strategy. His Majesty's Government of Nepal, Ministry of Forests and Soil Conservation (HMGN/MFSC), Kathmandu, Nepal.

HMGN/ADB/FINNIDA. 1988. Master Plan for Forestry Sector, Nepal. His Majesty's Government of Nepal (HMGN), Ministry of Forests and Soil Conservation, Kathmandu, Nepal.

Hummel, S. and O'hara, K. L. 2008. Forest management. Encyclopedia of Ecology 2: 1653-1662.

Hummel, S., Hudak, A. T., Uebler, E. H., Falkowski, M. J., and Megown, K. A. 2011. A comparison of accuracy and cost of LiDAR versus stand exam data for landscape management on the malheur national forest. Journal of forestry 109 (5): 267-273.

IPCC. 2006. IPCC Guidelines for National Greenhouse Gas Inventories. Volume 4: Agriculture, Forestry and Other Land Use, Chapter 4: Forest Land. Online at: http:// www.ipcc-nggip.iges.or.jp/public/2006gl/ pdf/4_Volume4/V4_04_Ch4_Forest_Land.

IPCC. 2007. Summary for Policymakers in Climate Change: The Physical Science Basis.Contribution of working group 1 to the fourth assessment report of Intergovernmental Panel on Climate Change (IPCC).

Jhingan, M. L. 2002. Advance Economic Theory. Virinda publications (p.) ltd. www. virindaindia.com. 11th revised and enlarged edition.

Joshi, G. R. and Bhatta, N. 2010. Early Action Forest Carbon Project to Prepare for REDD+ and Have an Equitable Carbon Financing Mechanism in Place: Climate, 
Community and Biodiversity Benefits. WWF Nepal.

Junttlia, V., Maltamo, M. and Kuranne, T. 2008. Sparse Bayesian estimation of forest stand characteristics from airborne laser scanning. Forest Science 54 (5): 543-552.

Junttlia, V., Kuranne, T. and Leppa "nen, V. 2010. Estimation of Forest Stand Parameters from Airborne Laser Scanning Using Calibrated Plot Databases. Forest Science 56 (3): 257-270.

Kandel, P. N. 2010. An Assessment of Data Needs. A study report published by Forest Resource Assessment (FRA) Nepal Project, Department of Forest Research and Survey (DFRS), Ministry of Forests and Soil Conservation, Kathmandu, Nepal. http:// www.franepal.org/articles/Data\%20needs.

Kangas, A. 1993. Estimating the parameters of systematic cluster sampling by model based inference. Scandinavian Journal of Forestry Research 8: 571-582.

Kangas, A. and Maltamo, M. 2006. Managing Forest Ecosystems: Forest Inventory Methodology and Applications. Published by Springer, P.O.Box 17, 3300. AA Dordrecht, The Netherlands. www.springer.com.

Köhl, M., Lister, A., Scott, C. T., Baldauf, T. and Plugge, D. 2011. Implications of Sampling Design and Sample Size for National Carbon Accounting Systems. http://www. cbmjournal.com/content/6/1/10.

Lebanon, G. 2010. Bias, Variance, and MSE of Estimators. http://www.cc.gatech.edu/ lebanon/notes/estimators1.pdf.

Lim, K., Treitz, P., Baldwin, K., Morrison, I. and Green, J. 2003. LiDAR remote sensing of biophysical properties of tolerant northern hardwood forests. Canadian Journal on Remote Sensing 29: 658-678.

Moore, D. S. and McCabe, G. P. 2001. Introduction to the Practice of Statistics. ISBN: 0-7167-3409-5. The third edition. www.whfreeman.com/statistics.
Næsset, E. 2002a. Predicting forest stand characteristics with airborne laser scanning using a practical two-stage procedure and field data. Remote Sensing Environment 80: 88-99.

Næsset, E. 2002b. Determination of mean tree height of forest stands by means of digital photogrammetry. Scandinavian Journal of Forestry Research 17: 446-459.

Næsset, E. 2009. Effects of different sensors, flying altitudes, and pulse repetition frequencies on forest canopy metrics and biophysical stand properties derived from small-footprint airborne laser data. Remote Sensing Environment 113:148-159.

Nelson, R., Valenti, M. A., Short, A. and Keller, C. 2003. A multiple resource inventory of Delaware using airborne laser data. Bioscience 53: 981-992.

Pascual, C., García-Abril, A., Cohen, W. B. and Martín- Fernández, S. 2010. Relationship between LiDAR-derived forest canopy height and Landsat images. International Journal of Remote Sensing 31(5): 1261-1280.

Sharma, E. R. and Pukkala, T. 1990. Volume Equation and Biomass Prediction of Forest Trees of Nepal. Publication No.47, Forest Survey and Statistical Division, Ministry of Forests and Soil Conservation, Kathmandu, Nepal.

Tomppo, E., Haakana, M., Katila, M. and Perasaari, J. 2008. Managing Forest Ecosystems: Multisource National Forest Inventory. Springer Science + Business Media B.V. www.springer.com/series/6247.

UNFCCC. 2009. Methodological Guidance for Activities Relating to Reducing Emissions from Deforestation and Forest Degradation and the Role of Conservation, Sustainable Management of Forests and Enhancement of Forest Carbon Stocks in Developing Countries. Decision 4/CP.15, Conference of Parties (COP 15), Copenhagen, Denmark. 